Review Article

\title{
Upgrading of Carbohydrates to the Biofuel Candidate 5-Ethoxymethylfurfural (EMF)
}

\author{
Xiaofang Liu $(\mathbb{D})$ and Rui Wang \\ Guizhou Engineering Research Center for Fruit Processing, Food and Pharmaceutical Engineering Institute, Guiyang University, \\ Guiyang 550005, China \\ Correspondence should be addressed to Xiaofang Liu; liuxfzap@163.com
}

Received 16 September 2018; Revised 8 November 2018; Accepted 19 November 2018; Published 17 December 2018

Guest Editor: Masaru Watanabe

Copyright ( 92018 Xiaofang Liu and Rui Wang. This is an open access article distributed under the Creative Commons Attribution License, which permits unrestricted use, distribution, and reproduction in any medium, provided the original work is properly cited.

\begin{abstract}
5-Ethoxymethylfurfural (EMF), one of the significant platform molecular derivatives, is regarded as a promising biofuel and additive for diesel, owing to its high energy density $\left(8.7 \mathrm{kWh} \cdot \mathrm{L}^{-1}\right)$. Several catalytic materials have been developed for the synthesis of EMF derived from different feedstocks under relatively mild reaction conditions. Although a great quantity of research has been conducted over the past decades, the unsatisfactory production selectivity mostly limited to the range $50 \%-70 \%$, and the classic fructose used as the substrate restricted its application for fuel manufacture in large scale. To address these production improvements, this review pays attention to evaluate the activity of various catalysts (e.g., mineral salts, zeolites, heteropolyacid-based hybrids, sulfonic acid-functionalized materials, and ionic liquids), providing potential research directions for the design of novel catalysts for the achievement of further improved EMF yields.
\end{abstract}

\section{Introduction}

Diminishing fossil reserves and growing environmental problems have determined research for sustainable, green, and environmentally benign resources for liquid fuels and chemicals [1-3]. Biomass is widely available, inexpensive, and a $\mathrm{CO}_{2}$-neutral source of carbon, the catalytic conversion of which to platform chemicals has potential to substitute the products from nonrenewable fossil sources [4-6]. A large number of strategies have been investigated for the conversion of carbohydrates in lignocellulosic biomass into chemicals and fuels [7-9]. The choice of an appropriate catalyst plays a significant role in observing high conversion and selectivity to the target chemicals in a sustainable, green, and economic process [10].

The main purpose of this review is to evaluate the activity of various catalysts (e.g., mineral salts, zeolites, heteropolyacidbased hybrids, sulfonic acid group-functionalized materials, and ionic liquids) with different catalytic effects and functional groups for the production of EMF from HMF, fructose, glucose, and other carbohydrates under the applied reaction conditions, providing potential research directions for the design of novel catalysts for the achievement of further improved EMF yields. Fossil fuels and the derived chemicals have been produced from the limited natural sources. Increasing demand for limited fossil fuels and environmental degradation is gradually severe. Thus, replacing the fossil fuels with alternative and sustainable energy sources is imperative $[11,12]$. Biomass is regarded as the only sustainable source of organic carbon compounds that have been suggested as the ideal equivalent to petroleum for the synthesis of fuels and chemicals. Biomass is widely existing and available as a proper feedstock, whose production estimates $1.0 \times 10^{11}$ tons per year. Extensive research and studies have been conducted to produce biofuels and biodegradable products from biomass [13-15].

Among multiple furan derivatives derived from biomass, EMF is recognized as an excellent additive for regular diesel with promising properties as follows: 
(i) With high boiling point $(508 \mathrm{~K})$ in comparison with diesel fuel.

(ii) High energy density $\left(30.3 \mathrm{MJ} \cdot \mathrm{L}^{-1}\right)$ is similar to regular gasoline $\left(31.9 \mathrm{MJ} \cdot \mathrm{L}^{-1}\right)$ and is compared to diesel fuel $\left(33.6 \mathrm{MJ} \cdot \mathrm{L}^{-1}\right)$, which is notably higher than ethanol $\left(21 \mathrm{MJ} \cdot \mathrm{L}^{-1}\right)[16]$.

(iii) Due to its low toxicity, EMF can be used as a flavor and aroma ingredient in the food beverage industries [17-21].

(iv) To blend EMF with diesel fuel in a diesel engine reduces the formation of particulate contamination, $\mathrm{SO}_{2}$ emissions, and soot. Meanwhile, EMF-blended fuel can make the engine run smoothly for hours $[11,12,22,23]$.

(v) Ethers that included EMF have a high cetane number [16], which is a very important factor for combustion performance and emission.

(vi) No hydrogenation step is required in EMF production, which is an advantage over other fuel additives (e.g., DMF) obtained from HMF production.

Considering the fact that EMF plays a significant role as a fuel candidate, diesel fuel additive [24], FDCA, or cyclopentenones precursor $[25,26]$, it is vital to review their different production aspects with detailed attention. Thus, recent progress in EMF synthesis is summarized in this review.

\section{Synthesis of EMF}

In order to produce EMF, HMF should participate in the etherification reaction with ethanol in the presence of an acid catalyst. Fructose or glucose may also be used as an initiator feed in large scale because their price is considerably low compared to fructose and HMF. Production of EMF from disaccharides, polysaccharides, and biomass through a "one-pot" approach is economically desirable due to the fact that the costs of saccharification, sugar isolation, and purification can be eliminated. However, the yield of synthesized EMF decreases significantly when HMF or fructose has not been used as the feed, and the possible reaction pathways for the synthesis of EMF from carbohydrates are presented in Scheme 1. The proposed reaction mechanism of hexose conversion to EMF is shown in Scheme 2.

Another method to produce EMF from different feedstocks is to follow a multistep mechanism. In the first step of the mechanism, an intermediate is produced, and then the intermediate is converted to EMF at very high yield. A representative example of the multistep method is found in the preparation of halomethylfurfural, namely, 5-chloromethylfurfural (CMF), where the reaction of biomass, polysaccharides, or $\mathrm{C} 6$ sugars with $\mathrm{HCl}$ leads to the production of CMF, and then, EMF is produced by nucleophilic substitution of CMF with ethanol [27]. Herein, we reviewed and compared different acid catalysts and their efficacies on the production yields of EMF from various feedstocks. Optimal reaction conditions for the case were presented.
2.1. Homogeneous Mineral Salts. Soluble catalysts or the homogeneous catalysts possessed excellent catalytic performance and the fast reaction rate, the existent ions of which are highly dispersed through the medium to enhance the availability of active sites with reactants. Generally, mineral salts acted as Lewis acid in favor of converting the glucose-based substrates to synthesize EMF. However, the separation and recycle wasted energy are not catered to the green and sustainable development.

Additionally, the heterogeneous catalytic reaction caused lower corrosion for the environment and equipment. Therefore, much more researchers concentrated on solid acid catalysts and enhanced their performances and activities [28-30]. Reaction temperature plays a crucial role in carbohydrates transformation and EMF synthesis, and the temperature ranges from $70^{\circ} \mathrm{C}$ to $160^{\circ} \mathrm{C}$. The major byproducts existing in the system were EL, 5-(ethoxymethyl) furfural diethylacetal (EMFDEA) [17], and 5,5' (oxybis(methylene))bis-2-furfural (OBMF) [31].

Metal chloride always is a commercially available Lewis acid with low toxicity and a high catalytic activity for the conversion of hexoses. Series of metal chlorides have been introduced for the production of EMF (Scheme 3). Initially, Liu et al. [32] examined various inorganic salts to promote fructose into EMF with $\mathrm{NH}_{4} \mathrm{Br}, \mathrm{CuCl}_{2} \cdot 4 \mathrm{H}_{2} \mathrm{O}$, and $\mathrm{NiCl}_{2} \cdot 6 \mathrm{H}_{2} \mathrm{O}$ giving low yields of EMF. Among those mentioned above, $\mathrm{NH}_{4} \mathrm{Cl}$ demonstrated superior catalytic activity with $42 \%$ total yield of HMF and EMF under optimum reaction condition. Simultaneously, Yang et al. [33] chose the $\mathrm{AlCl}_{3} \cdot 6 \mathrm{H}_{2} \mathrm{O}$ as a catalyst for carbohydrates including glucose, sucrose, maltose, cellobiose, starch, and cellulose and converted to EMF in ethanol/water binary solvents. The higher total furans yield (included HMF and EMF) of 57\% was obtained, and a moderate EMF yield of $40 \%$ was derived from sucrose. However, the conversion efficiencies of other carbohydrates to furan were low. The highest EMF yield through single step reaction from $\mathrm{HMF}$ was proved to be $92.9 \%$ catalyzed by $\mathrm{AlCl}_{3}$ at $100^{\circ} \mathrm{C}$ for $5 \mathrm{~h}$ by Liu et al. [31]. With the same carbohydrates conversion system, Yu et al. [34] performed the use of largescale common metal salts as catalysts for the preparation of EMF to understand the catalytic mechanism. According to the research, $\mathrm{AlCl}_{3}$ gave good catalytic activity for producing EMF from fructose at $140^{\circ} \mathrm{C}$, while $\mathrm{CuSO}_{4}$ and $\mathrm{Fe}_{2}\left(\mathrm{SO}_{4}\right)_{3}$ provided comparable EMF yields at 110 to $120^{\circ} \mathrm{C}$, and the latter favored the EL formation.

To enhance the catalytic performance, Jia et al. [35] explored combinations of $\mathrm{AlCl}_{3}$ with different cocatalysts such as $\mathrm{B}(\mathrm{OH})_{3}$ and $\mathrm{BF}_{3} \cdot(\mathrm{Et})_{2} \mathrm{O}$ or halide salts such as $\mathrm{NaF}$, $\mathrm{NaCl}$, and $\mathrm{NaBr}$. The result of $\mathrm{BF}_{3} \cdot(\mathrm{Et})_{2} \mathrm{O} / \mathrm{AlCl}_{3} \cdot 6 \mathrm{H}_{2} \mathrm{O}$ proved to be significantly superior to other catalysts; $55.0 \%$, $45.4 \%$, and $23.9 \%$ high yields of EMF derived from fructose, inulin, and sucrose were achieved, respectively, under the optimized conditions. Later, Zhou et al. [36] studied the reactivity of $\mathrm{FeCl}_{3}, \mathrm{CrCl}_{2}, \mathrm{GeCl}_{4}, \mathrm{IrCl}_{3}$, and so on for the production of EMF. The presented toxicity, high price, and instability drawbacks of other metal chlorides affect the further exploration. In the presence of $\mathrm{FeCl}_{3}$, a maximum EMF yield of $30.1 \%$ was obtained in the mixture solvent composed of $[\mathrm{Bmim}] \mathrm{Cl}$ and ethanol. 

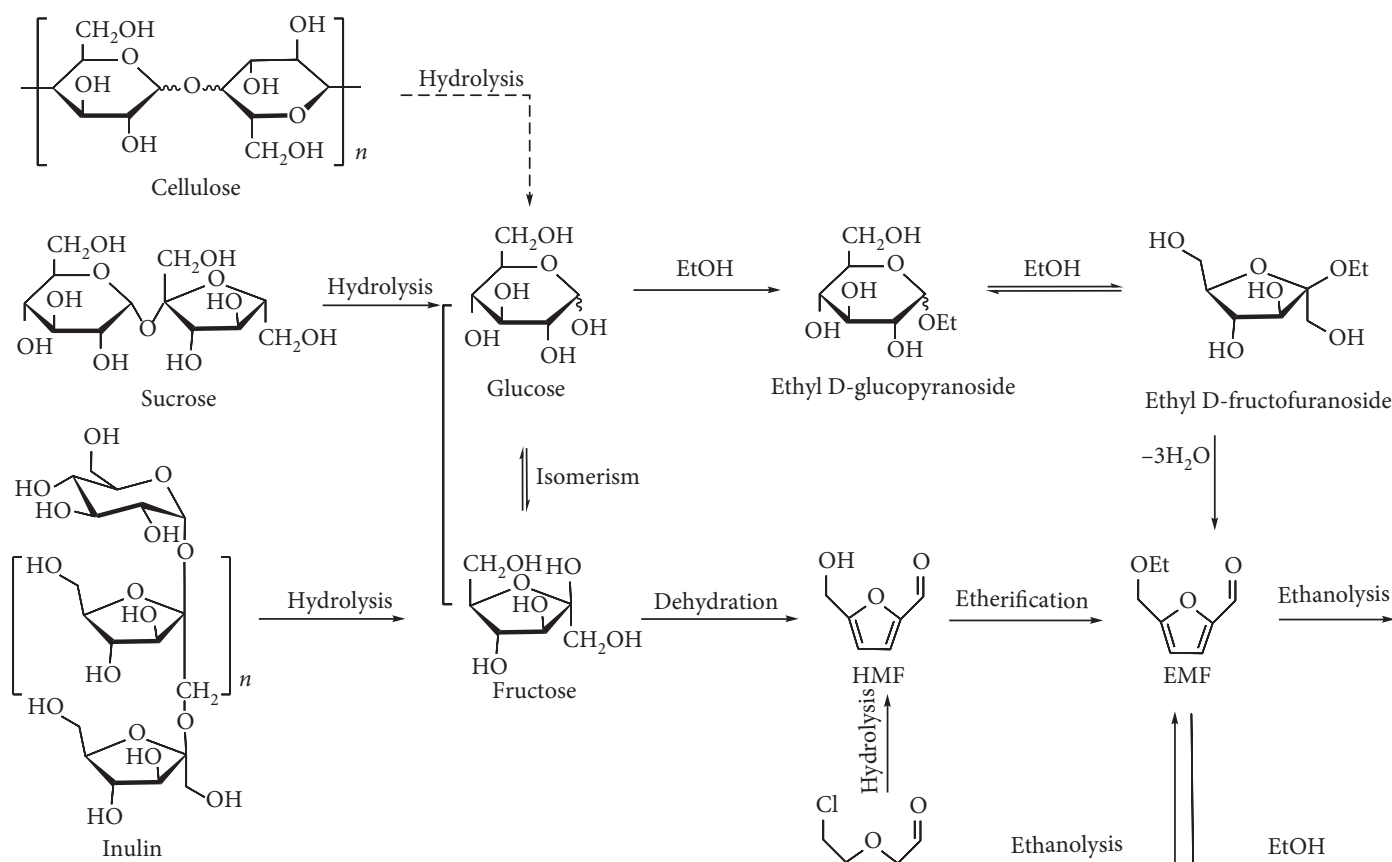

Glucose

Ethyl D-glucopyranoside

Ethyl D-fructofuranoside

$$
\text { \|Isomerism }
$$

$-3 \mathrm{H}_{2} \mathrm{O}$
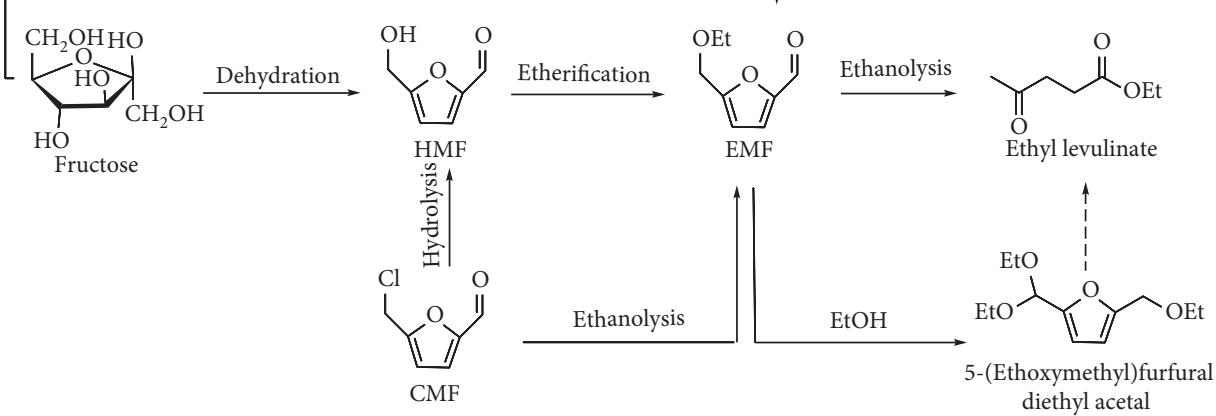

Scheme 1: Reaction pathways for the synthesis of EMF from carbohydrates.

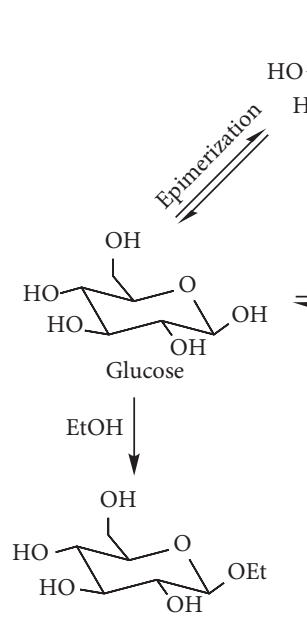

Ethyl-D-glucopyranoside (EDGP)
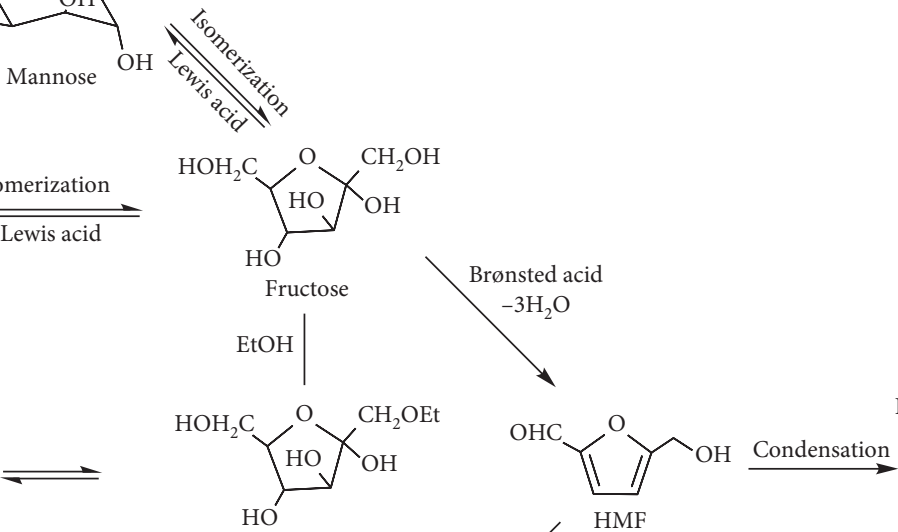
HMF

Ethyl-D-fructofuranoside (EDFF)

Brønsted acid EtOH

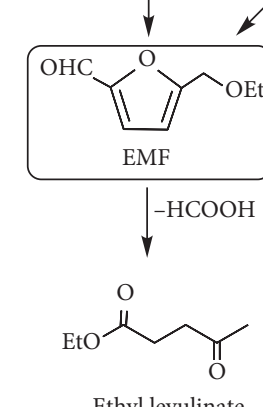

Ethyl levulinate

(EL)

Scheme 2: Proposed mechanism for one-pot conversion of hexose to EMF. 


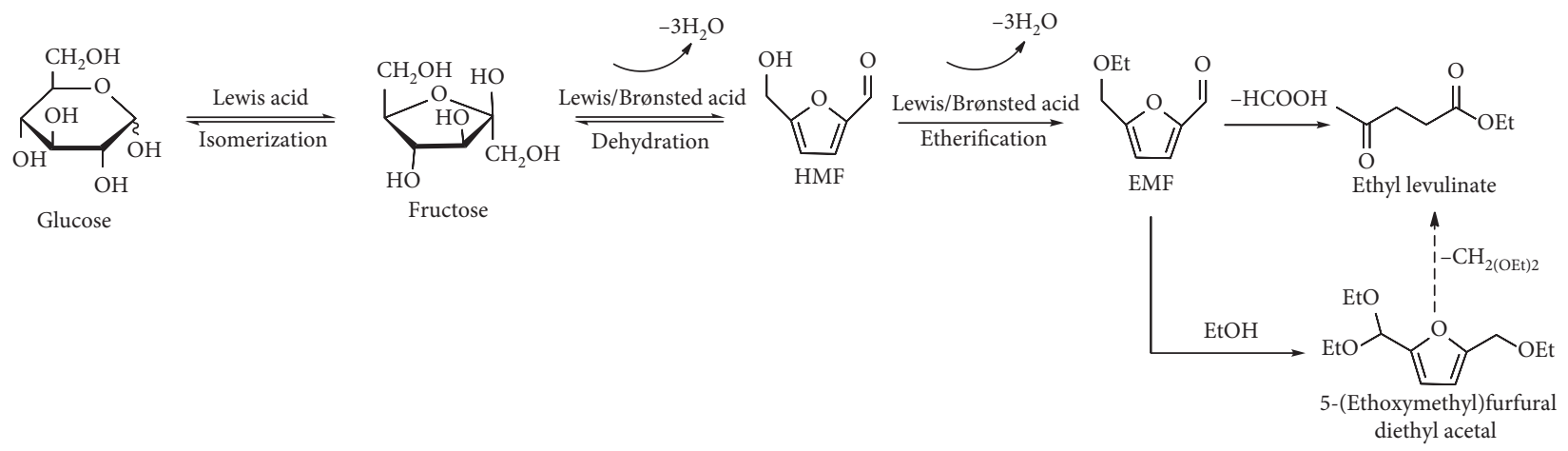

Scheme 3: Reaction pathways for the conversion of hexose to EMF catalyzed by Lewis acid.

\subsection{Heterogeneous Catalysts}

2.2.1. Zeolitic Catalysts. Zeolites with the highly dispersed and uniform channel microporous structure typically restrict the formation of large and unwanted by-product for the EMF preparation system. Meanwhile, the micropores also limit the effective diffusion of HMF and EMF due to the molecular sizes and small pore openings of zeolites $[37,38]$. Expansion of the pore sizes needed to be further explored for the application in more areas.

The enlarged pore sizes play an important role for these materials. For instance, Lanzafame et al. [29] conducted the efficient etherification of HMF catalyzed by mesoporous AlMCM-41 (with different Si/Al ratios), zirconia, or sulfated zirconia immobilized on SBA-15. Strong Lewis acid sites $\mathrm{ZrO}_{2}$ and isolated $\mathrm{Al}^{3+}$ sites were explained to be beneficial for EMF production. In addition, strong Brønsted acid sites led to the formation of ethyl 4-oxopentanoate. Investigation on mesoporous aluminosilicates by further introducing aluminum into the framework Al-TUD-1 (Si/Al ratio: 21) was carried out by Neves et al. [39]. Based on the unique and regular channel of MCM-41, Che et al. [30] illustrated a nanosphere catalyst with highly dispersed $\mathrm{H}_{4} \mathrm{SiW}_{12} \mathrm{O}_{40} /$ MCM-41 for the etherification of the hydroxyl group of $\mathrm{HMF}$. Comparing the catalytic performance with $p$-TSA, $\mathrm{H}_{2} \mathrm{SO}_{4}$, Amberlyst-15, and $\mathrm{H}_{3} \mathrm{PO}_{4}, \mathrm{H}_{4} \mathrm{SiW}_{12} \mathrm{O}_{40} / \mathrm{MCM}-41$ showed $84.1 \%$ selectivity to EMF with $92.0 \%$ conversion of HMF under mild conditions. Meanwhile, the intermediate $5,5^{\prime}$ (oxybis(methylene))bis-2-furfural could also be converted to target product EMF. They found that, with the strength of acids and heteropoly anion effects, the effective catalytic performance of $\mathrm{H}_{4} \mathrm{SiW}_{12} \mathrm{O}_{40} / \mathrm{MCM}-41$ was obtained. In this regards, Liu et al. [40] developed MCM-41HPW with different dosages of phosphotungstic acid (HPW) supporting on MCM-41. The optimal 40 wt.\% MCM-41HPW achieved a high EMF yield of $83.4 \%$, converted from $\mathrm{HMF}$ at $100^{\circ} \mathrm{C}$ for $12 \mathrm{~h}$.

Inspired by the published results that tin-containing zeolite (Sn-BEA) was effective for the glucose-fructoseHMF conversion, Lew et al. [41] further employed SnBEA combined with Amberlyst-131 for one-pot glucoseto-fructose-to-HMF-to-EMF conversion, giving $31 \%$ yield of EMF. Li et al. [42] found DeAl-H-beta could provide a moderate EMF yield (43\%) from sucrose, and the EMF yield was improved up to $50 \%$ by a one-pot two-step method. However, poor catalytic performance was achieved using cellobiose as a substrate for EMF. Lewis et al. [43] explored a series of zeolites including $\mathrm{Hf}-, \mathrm{Zr}-, \mathrm{Ti}-, \mathrm{Ta}-, \mathrm{Nb}-$, and $\mathrm{Sn}-$ Beta that could promote the etherification reaction of HMF. Under batch conditions, Ta-Beta and Al-Beta showed comparable EMF yields of $56 \%$ and $41 \%$, respectively.

Product selectivity depends on the control of active sites strength. Barbera et al. [44] introduced $\mathrm{NH}_{4}$-exchanged zeolites, and the $\mathrm{NH}_{4}$ was used to block the strong sites, thus preventing the secondary reactions. The results proved that $\mathrm{NH}^{4+}$ effectively increased the product selectivity of $\mathrm{NH}_{4}$ BEA catalyst for HMF etherification reaction. Recently, Bai et al. [45] exhibited the glucose conversion to EMF catalyzed by multifunctional MFI-Sn/Al zeolite with dual meso-/ microporosity and dual Lewis and Brønsted acidity. Combination of Lewis acidic $\mathrm{Sn}$ and $\mathrm{Al}$ sites and Brønsted acidic $\mathrm{Al}-\mathrm{O}(\mathrm{H})-\mathrm{Si}$ sites was efficient for the cascade isomerizationdehydration-etherification reaction, affording 44\% EMF yield.

2.2.2. Heteropolyacid-Based Hybrid Catalysts. Heteropolyacids have several advantages such as strong Brønsted acidity, tunable acid-base properties, and high proton mobility. But, they tend to dissolve in water and polar solvents and possess low surface area and low thermal stability, which limits their application in catalytic conversion. Supporting a solid support is a method that has been used by different groups.

Originally, Yang et al. [46] investigated the fructoseEMF transformation in a mixed ethanol/THF (tetrahydrofuran) medium catalyzed by $\mathrm{H}_{3} \mathrm{PW}_{12} \mathrm{O}_{40}$ (HPW). The microwave offered EMF in yield of $76 \%$ under the optimum reaction condition, and the cosolvent THF significantly increased fructose conversion. Wang et al. [47] compared the activity of HPW, phosphomolybdic acid (HPM), $\mathrm{AlCl}_{3}$, $\mathrm{H}_{3} \mathrm{PO}_{4}$, and Amberlyst-15 for production of EMF from fructose in an ethanol/DMSO mixture. Results indicated that HPW and HPM exhibited superior catalytic activities than $\mathrm{AlCl}_{3}, \mathrm{H}_{3} \mathrm{PO}_{4}$, and Amberlyst-15, and the former formed $64 \% \mathrm{EMF}$ within $130 \mathrm{~min}$ at $140^{\circ} \mathrm{C}$. In this regard, Ren et al. [48] exchanged $\mathrm{H}^{+}$ion of $\mathrm{HPW}$ with $\mathrm{Ag}^{+}$and achieved $\mathrm{Ag}_{1} \mathrm{H}_{2} \mathrm{PW}$, which presented a high activity and EMF yield of $88.7 \%$. Further replacing another $\mathrm{H}^{+}$in the 
$\mathrm{Ag}_{1} \mathrm{H}_{2} \mathrm{PW}$, the acid strength of the catalyst decreased. Ren et al. used $\mathrm{Ag}_{1} \mathrm{H}_{2} \mathrm{PW}$ catalyst for fructose dehydration and $\mathrm{HMF}$ etherification, and a relatively high yield of EMF (69.5\%) was obtained.

Stability and efficient separation are crucial criteria to be the catalyst support. Addition of heteropolyacid into $\mathrm{Fe}_{3} \mathrm{O}_{4} @ \mathrm{SiO}_{2}$, simultaneously with the introduction of the silica layer could modify the MNPs-formed inert surface. $\mathrm{Fe}_{3} \mathrm{O}_{4} @ \mathrm{SiO}_{2}-\mathrm{HPW}$ catalyzed the reaction of $\mathrm{HMF}$ with ethanol, and therefore, the activity increased dramatically and the production of EMF yield reached 83.6\% [49]. Wang et al. [50] also applied $\mathrm{Fe}_{3} \mathrm{O}_{4} @ \mathrm{SiO}_{2}-\mathrm{HPW}$ for EMF production from HMF to obtain the same effect, which was in accordance with the results of Liu and Zhang [51]. Besides, $\mathrm{Fe}_{3} \mathrm{O}_{4} @ \mathrm{SiO}_{2}-\mathrm{HPW}$ achieved an EMF yield of $54.8 \%$ derived from fructose.

Organic-inorganic hybrid materials become the hotspot to be the catalyst, for instance, HPA-based $[\mathrm{MIMBS}]_{3} \mathrm{PW}_{12} \mathrm{O}_{40}$ hybrid catalyst reported by Liu et al. [52] for the preparation of EMF. Combination of IL with $\mathrm{H}_{3} \mathrm{PW}_{12} \mathrm{O}_{40}$ enhanced the EMF yield to $90.7 \%$ with $98.1 \%$ conversion of $\mathrm{HMF}$ under the optimum reaction condition at $70^{\circ} \mathrm{C}$ within $24 \mathrm{~h}$. Wang et al. [53] studied the uniform nanospheric hybrids by controlling the molar ratio of phosphotungstic acid (HPW) and pyridine (PY) or trimethylamine (TEA) in different nanosizes. Particularly, PYPW-1 showed an excellent catalytic activity with $90 \%$ of EMF, which attribute to the relatively strong acidity and regular pore size. With the prepared nanosphere PY-PW-1, fructose was also converted to EMF in one-pot reaction process and obtained a moderate yield of $55 \%$ with the enhanced temperature at $120^{\circ} \mathrm{C}$.

The synthesized K-10 clay-HPW not only avoided the HPW being dissolved into polar organic solvents and expressed the high activity. Liu et al. [54] used $30 \mathrm{wt} \%$ of K-10 clay-HPW for HMF-EMF transformation. Under the optimum reaction conditions $\left(100^{\circ} \mathrm{C}, 10 \mathrm{~h}\right)$, catalytic activity was increased to $91.5 \%$ yield, whereas for one-pot fructose conversion to EMF, $61.5 \%$ yield of EMF was gained. The prepared catalyst with high stability could be reused several times without loss of catalytic performance. MCM-41 with uniform channel structure and pore size was suitable to support 12-tungstophosphoric acid that allowed the one-pot conversion of fructose directly into EMF, leading to $42.9 \%$ EMF by 40 wt.\% MCM-41-HPW [40].

Apart from K-10 clay and MCM-41, MOF-based [Cu-BTC][HPM] (NENU-5) was also efficient for the etherification of HMF to EMF with up to $68.4 \%$ yield under normal pressure and optimized conditions (Figure 1). Benefiting from the unique structure, MOFs can provide adsorption sites for HPM to avoid HPM dissolving into solvents, making the catalysts be recyclable with 55\% EMF yield [55].

The addition of cosolvent exhibits improvement in EMF yield as compared with the single solvent, and enhanced yield of EMF ranges from 5 to 20 percentages. Xu et al. [56] explored the ethanol $/ n$-hexane mixture solvent indicating that the introduction of $n$-hexane could enhance the yield of EMF to $66.3 \%$ with optimum volume ratio (ethanol:n- hexane, $6: 4$ ), conducted at $120^{\circ} \mathrm{C}$ within $180 \mathrm{~min}$. With the ethanol-DMSO mixture, Li et al. [57] also developed acidbase bifunctional hybrid nanosphere catalyst Lys/PW that possessed an optimal reaction activity of 76.6\% EMF yield from fructose, implying that the base sites of the catalysts play an important role in increasing EMF stability.

Combination of Lewis acid $\mathrm{AlCl}_{3} \cdot 6 \mathrm{H}_{2} \mathrm{O}$ and Brønsted solid acid PTSA-POM proved cooperative effect for glucose transformation into EMF and generated 30.6\% EMF under the ethanol-water $(9: 1)$ system. [58].

The appropriate supports play a vital role in heteropolyacid as the active center producing EMF. Partial substitution of protons is another effective approach to change the property of heteropolyacid for better catalytic activity. Raveendra et al. [59] reported the cesium-exchanged silicotungstic acid to enhance the surface area and acidity and finally obtained $91 \%$ EMF yield with $\mathrm{Cs}_{2} \mathrm{STA}$ at $120^{\circ} \mathrm{C}$ for $2.5 \mathrm{~h}$.

\subsubsection{Sulfonic Acid-Functionalized Catalysts. The strong} acidity of sulfonic acid groups can be immobilized onto the diverse supporter by sulfonation reactions and hence gain multiple sulfonic acid-functionalized catalysts. Simultaneously, the acidic density can be flexibly controlled by the dosage of sulfonic sources. Considering the green and sustainable development request, loss of element $\mathrm{S}$ was not catered for the present development.

Magnetic carriers to load sulfonic acid groups can be easily separated by a permanent magnet and recycled for times without loss of activity attracting much attention of scientists. Zhang et al. [60] chose $\mathrm{Fe}_{3} \mathrm{O}_{4} @ \mathrm{SiO}_{2}$ for preparation supporting a high yield (up to 89.3\%) of EMF converted from HMF. Magnetic nanoparticles (MNPs) and amorphous carbon were selected to immobilize sulfonic acid groups $\left(-\mathrm{SO}_{3} \mathrm{H}\right)$ which act as a solid acid catalyst for EMF production [61]. Successfully, $\mathrm{Fe}_{3} \mathrm{O}_{4} @ \mathrm{C}-\mathrm{SO}_{3} \mathrm{H}$ shared active catalytic properties in HMF-EMF, fructose-EMF, sucrose-EMF, and inulin-EMF systems, and considerable yields of $88.4 \%, 67.8 \%, 33.2 \%$, and $58.4 \%$ were obtained, respectively. Among those, the low yield of EMF was produced from sucrose owing to the composition of sucrose, which contains one fructose and glucose unit, and glucose cannot be converted to EMF directly. The more deep-seated research was carried out by $\mathrm{Fe}_{3} \mathrm{O}_{4} @ \mathrm{SiO}_{2}-\mathrm{SH}-$ Im- $-\mathrm{HSO}_{4}$ [62] and facilitated by it, indicating that EMF yields derived from inulin (56.1\%) and fructose were consistent while glucose always promoted to ethyl glucoside. Soon afterward, Wang et al. [63] illustrated the smooth conversion of sucrose and inulin with superior catalytic performance offering $53.6 \%$ and $26.8 \%$ EMF yields, respectively, at $140^{\circ} \mathrm{C}$ for $24 \mathrm{~h}$. Excellent catalytic performance of $\mathrm{OMC}-\mathrm{SO}_{3} \mathrm{H}$ indicated its promising application for biomass conversion into value-added chemicals and liquid fuels.

Considering the sustainable and green development trend, the same magnetic $\mathrm{Fe}_{3} \mathrm{O}_{4} @ \mathrm{C}-\mathrm{SO}_{3} \mathrm{H}$ prepared from wheat straw biomass afforded comparable EMF yield of $64.2 \%$ in DMSO-ethanol binary solvent. Bearing multiple 


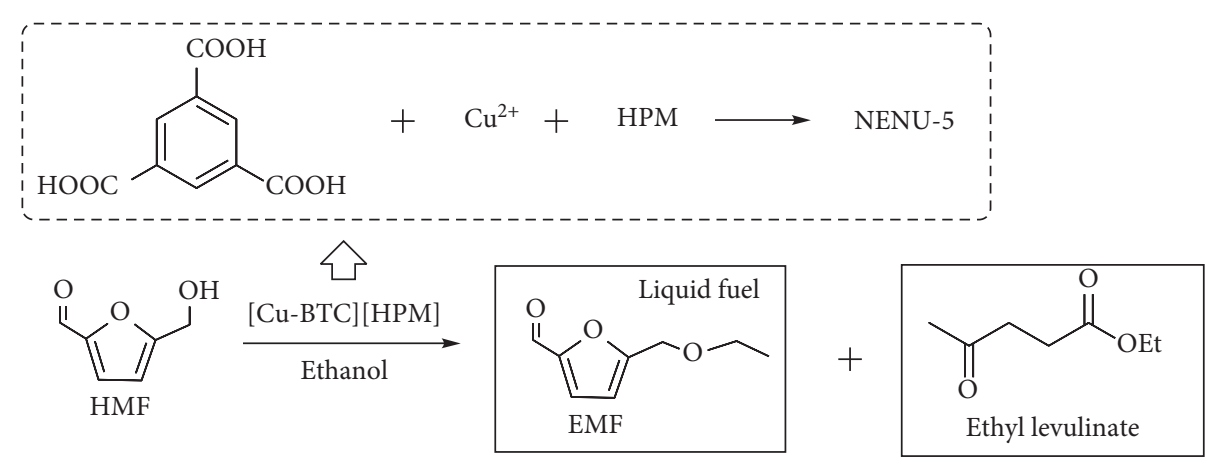

FIGURE 1: Schematic of the catalyst preparation and catalytic procedure.

$-\mathrm{COOH},-\mathrm{SO}_{3} \mathrm{H}$, and $-\mathrm{OH}$ groups, the authors described the progress of fructose or HMF to EMF in relatively high yields with $64.2 \%$ and $85.6 \%$ [64].

Grafting sulfonic acid onto the inorganic insoluble supports is a technique to prepare high-performance heterogeneous solid acidic catalysts. Liu and Zhang [51] studied the grafting of sulfonic acid onto the mesoporous silica and utilized for effective etherification of HMF for EMF with $83.8 \%$ under the optimal conditions $\left(100^{\circ} \mathrm{C}, 10 \mathrm{~h}\right)$, while the high yields of $63.1 \%$ and $60.7 \%$ were synthesized by one-pot transformation of fructose and inulin. However, the aldosebased carbohydrates such as glucose were mainly turned to ethyl D-glucopyranoside with a high yield of $91.7 \%$. The unique properties such as $2 \mathrm{D}$ structure, high stability, and high surface areas decided GO as a promising catalytic material that was oxidized by Hummers' method clarified the engineered catalytic performance for the conversion of HMF into EMF with high yield of EMF (92\%), while EMF yield was decreased when fructose replaced HMF as a starting material [65] (Figure 2). Under mixture solvent ethanol-DMSO in 3:7, furan selectivity enhanced to $71 \%$ EMF yield and 34\%, and 66\% EMF yields were achieved when sucrose and inulin were used as the substrates. Partially reducing $\mathrm{GO}$, amorphous carbon black $(\mathrm{CB})$, and carbon nanotubes (CNTs) by sulfuric acid (S-RGO) were conducted for the synthesis of EMF converted from HMF. The catalytic activity of S-RGO proved to be superior to S-CB, S-CNTs, and even the classic Amberlyst-15 [66].

Besides, new solid acid catalysts obtained by sulfonating natural biopolymers met the green trend for biomass conversion to high value-added chemicals. Liu et al. [67] developed the cellulose sulfuric acid for the etherification of HMF for the synthesis of EMF and observed high yield $(84.4 \%)$ under optimized condition. Similarly, application of glucose-derived magnetic solid acid, glu- $\mathrm{Fe}_{3} \mathrm{O}_{4}-\mathrm{SO}_{3} \mathrm{H}$, also acted as an etherification catalyst and generated $92 \%$ isolated yield EMF [68]. With the optimal $50 \mathrm{wt} \%$ loading rate of glu- $\mathrm{Fe}_{3} \mathrm{O}_{4}-\mathrm{SO}_{3} \mathrm{H}$, EMF from fructose was effectively produced by $81 \%$ yield.

Amberlyst-15 as one of the standard solid acid catalysts was applied in various reaction systems and first explored by Zhu et al. [69] for the HMF-5-methoxymethylfurfural (MMF) conversion in low-boiling point solvent. The presence of cosolvent THF enhanced the contact of $-\mathrm{SO}_{3} \mathrm{H}$ of Amberlyst-15 leading to promoting the catalytic progress

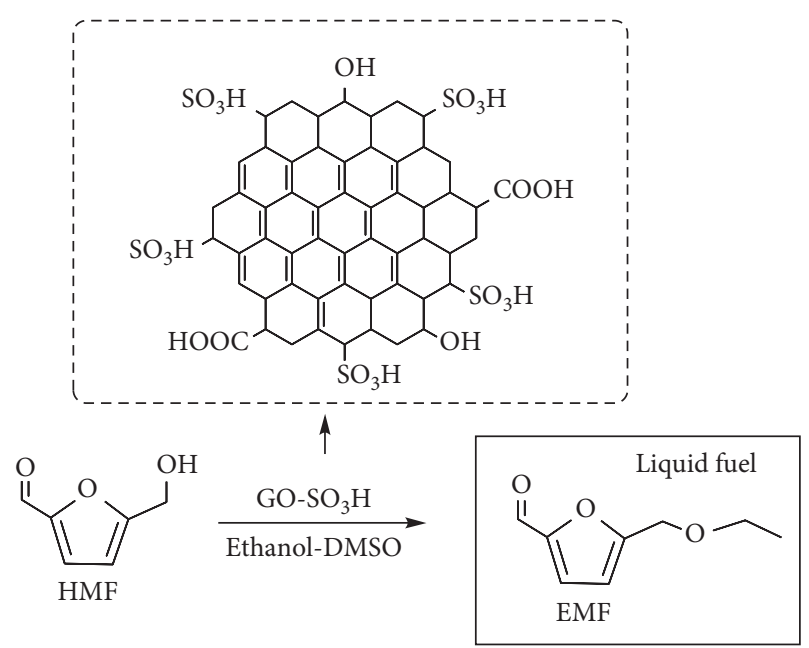

FIgURE 2: The conversion of HMF to EMF catalyzed by GO- $\mathrm{SO}_{3} \mathrm{H}$.

and accumulating the target molecules. Because of short of the high surface area and the limited contact of active sites and substrate, the catalytic performance of Amberlyst-15 was dissatisfactory. MOF provided large enough specific surface area and acidic density, and MIL-101- $\mathrm{SO}_{3} \mathrm{H}(100)$ showed a better catalytic performance with $89.2 \%$ conversion of fructose and $67.7 \%$ EMF yield in the ethanol and THF mixture.

Well-defined structure and uniform distribution of active sites catalyst arenesulfonic acid-modified SBA-15 Ar- $\mathrm{SO}_{3} \mathrm{H}-\mathrm{SBA}-15$ was studied for the conversion of fructose to EMF in binary ethanol-DMSO solvent in optimizing reaction conditions (e.g., temperature, catalyst loading, and DMSO concentration), demonstrating the maximum EMF yield of $63.4 \%$ [70]. Li et al. [71] generated a series of $\mathrm{SO}_{3} \mathrm{H}$-functionalized polymer solid acid catalysts for successive fructose dehydration and HMF etherification, and an EMF yield of $72.8 \%$ was achieved with the optimal catalyst poly(VMPS)-PW at $110^{\circ} \mathrm{C}$ within $10 \mathrm{~h}$.

2.2.4. Ionic Liquid Catalysts. Due to the tailored design, good thermal and chemical stability, low melting point, and good solubility of acidic ionic liquids, the investigation of 


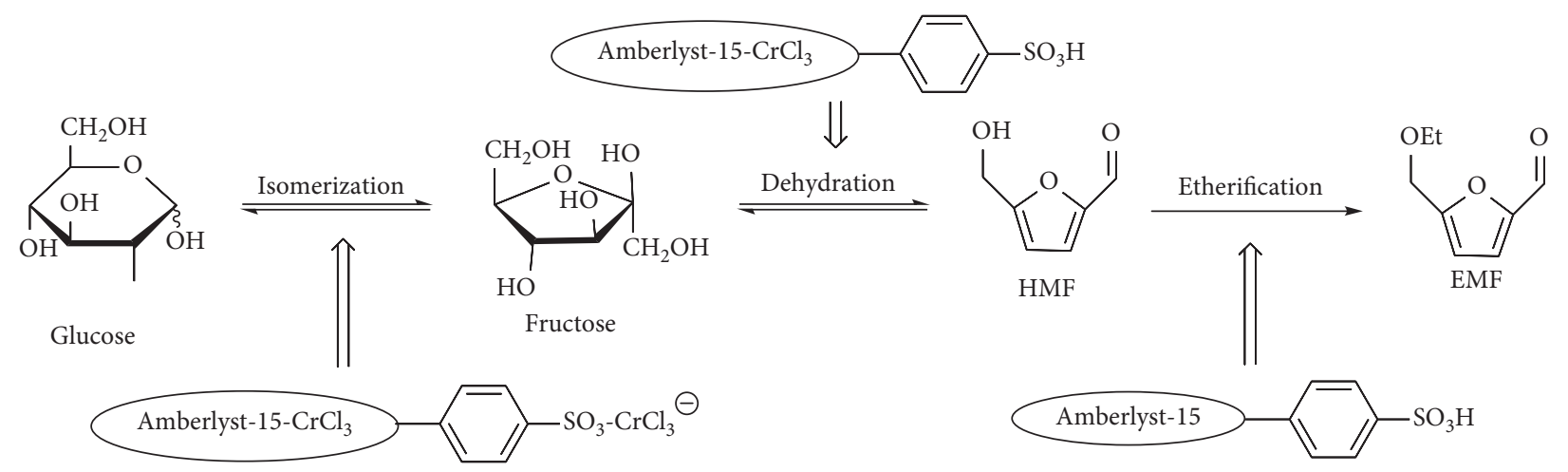

FIgURE 3: Schematic illustration of the catalysis progress.

them attracts much attention. The problem of high cost and recycle is urgently to be solved.

Kraus and Guney [72] appointed the sulfonic acidfunctionalized IL to catalyze the conversion of fructose for the EMF fabrication in a one-pot procedure without the addition of solvent or acid catalysts. The application of 1butyl-3-(3-sulfopropyl)-imidazolium chloride (4) and 1methyl-3-(3-sulfopropyl)-imidazolium chloride (5) for EMF provided comparable $55 \%$ and $54 \%$ yields under the mild condition $\left(100^{\circ} \mathrm{C}, 80 \mathrm{~min}\right)$, and the novel biphasic medium assembly of hexanes and IL enhanced the EMF yields to a certain extent.

The Brønsted acidic IL $[\mathrm{DMA}]^{+}\left[\mathrm{CH}_{3} \mathrm{SO}_{3}\right]^{-}$was effective for fructose-EMF conversion with a relatively high yield of $64 \%$, while one-pot cellulose transformation gave $22 \%$ yield of EMF [73]. Alam et al. [37] further showed EMF production directly from Foxtail and Red nut sedge weeds in presence of $[\mathrm{DMA}]^{+}\left[\mathrm{CH}_{3} \mathrm{SO}_{3}\right]^{-}$, which was better than $[\mathrm{NMP}]^{+}\left[\mathrm{CH}_{3} \mathrm{SO}_{3}\right]^{-}$when converting foxtail to EMF.

Except the ionic liquid catalysts, functionalized ionic liquids can also act as the reaction medium to afford efficient EMF yield. Guo et al. [74] chose hydrogen sulfate ionic liquid as a homogeneous catalyst and mixed with ethanol as a reaction solvent for efficient preparation of EMF. Catalyzed by the $\left[\mathrm{C}_{4} \mathrm{mim}\right]\left[\mathrm{HSO}_{4}\right]$-ethanol system, high yield of $83 \%$ EMF was observed from fructose at $130^{\circ} \mathrm{C}$ within $20 \mathrm{~min}$, which could be attributed to the acidity of $\left[\mathrm{C}_{4} \mathrm{mim}\right]$ $\left[\mathrm{HSO}_{4}\right]$, the viscosity of the mixture system, and the formed hydrogen bonds between $\left[\mathrm{C}_{4} \mathrm{mim}\right]\left[\mathrm{HSO}_{4}\right]$, ethanol solvent, and fructose.

Due to the superior physical and chemical properties and benefits of acidic ILs, an effective progress for EMF derived from carbohydrates by deep eutectic solvent (DES) mixture as a solvent was proposed [75]. 77.3\% EMF yield was gained with fructose as substrate catalyzed by Amberlyst-15, and more excellent catalytic performance afforded a high EMF yield of $46.7 \%$ obtained from glucose with $\mathrm{CrCl}_{3}$-modified Amberlyst-15 (Figure 3).

2.2.5. Others. Except for the mentioned catalysts in the previous section, there exist many other effective materials such as Zr-Mont, $\mathrm{Co}(x) \mathrm{Pc}, \mathrm{MoO}_{2} \mathrm{Cl}_{2}\left(\mathrm{H}_{2} \mathrm{O}\right)_{2}$, and a combination of metal chloride with resins which could be also used for carbohydrates transformation to EMF.

Acidic Zr-montmorillonite (Zr-Mont) catalyst was utilized for synthesis mixture of EMF and 2-(diethoxymethyl)5-(ethoxymethyl)furan by Shined and Rode [76], and the latter can turn into EMF by conducting in water with the same Zr-Mont. Under the optimized reaction conditions, EMF was observed in the highest yields of $91 \%$ by etherification HMF with ethanol. Yadav et al. [77] investigated the use of cobalt (I, II, III) phthalocyanine $(\mathrm{Co}(x) \mathrm{Pc})$ for the isomerization of glucose to fructose, for fructose dehydration, and in the subsequent etherification. It was noted that $\mathrm{Co}(x) \mathrm{Pc}$ was effective for the direct conversion of carbohydrates to EMF in [EMIM]Cl ionic liquid, and Co(III) Pc exhibited much higher catalytic activity. The levulinate could be reduced by the waste and basic additive oil shale ash, which is formed by burning oil shale in power plants, while it was efficient for the preparation of EMF with high yield and purity [78]. The final product EMF syntheses starting from 5-bromomethylfurfural (BMF) afforded 88\% yield without further purification which reacted under room temperature for $17 \mathrm{~h}$ in $96 \%$ ethanol.

Considering the excellent catalytic property for the reduction reaction, high valent oxomolybdenum complexes were investigated for the synthesis of EMF by one-pot fructose conversion in ethanol/THF $(5: 2)$ mixture and optimal yield of $53 \%$ was achieved within $17 \mathrm{~h}$ at $120^{\circ} \mathrm{C}$. With the efficient catalyst, $40 \%$ and $23 \%$ yield of EMF were produced from inulin and sucrose, respectively [79].

Marine carbohydrate agar derived from red algae was reported for production of EMF in the presence of [EMIM] $\mathrm{Cl}, \mathrm{CrCl}_{2}$, and Dowex resin mixture, afford isolate $3.9 \mathrm{~g}$ of EMF and EL (EMF to EL mole ratio: $5: 2$ ) from $10 \mathrm{~g}$ of agar [80]. Similarly, biomass wheat straw was directly converted by alcoholysis reaction in $94 \%(\mathrm{w} / \mathrm{w})$ ethanol with $30 \mathrm{mM}$ $\mathrm{H}_{2} \mathrm{SO}_{4}$ at $200^{\circ} \mathrm{C}$, and yields for EMF and by-product EL were $20 \%$ and $25 \%$, respectively [81].

\section{Conclusions}

As mentioned above, various Lewis and Brønsted acid catalysts have been conducted to convert HMF, fructose, and inulin in high yields without extra costs for isolation and purification. It is worth noting that HMF is not affordable as 
a feed for EMF production regardless of the high yields of 70\%-95\% reported for HMF etherification to EMF by different groups. The technoeconomic analysis carried out by Torres et al. [82] estimated the HMF price of $2.16 \$ / \mathrm{kg}$ based on the process proposed by Roman-Leshkov et al. [83]. EMF synthesis from fructose at a desirable yield of $50 \%-70 \%$, but high reaction temperature $\left(90-130^{\circ} \mathrm{C}\right)$ and retention time (6-24 h), is needed compared to the HMF cases. In general, EMF production derived from sucrose did not gain high yields, because of the fact that glucose obtained from sucrose conversion was not converted to EMF in good yields. Nevertheless, the fructose polymer inulin exhibited better performance and produced EMF at high yields. One-pot transformation of cellulose or biomass to EMF led to low yields, due to their complex structures with the low glucose conversion to EMF. Ethanol/THF or ethanol/DMSO mixture is applied as a reaction medium for EMF synthesis from fructose. In a series of reactions, EMF may also participate in the rehydration reaction to produce EL.

\section{Conflicts of Interest}

The authors declare that there are no conflicts of interest regarding the publication of this paper.

\section{Acknowledgments}

This work was financially supported by the Joint Science and Technology Funds of the Youth Growth S\&T Personnel Foundation of Guizhou Education Department (No. KY [2018]292), the Special Funding of Guiyang Science and Technology Bureau and Guiyang University (GYU-KYZ [2018]01-12), and the Technical Talent Support Program of Guizhou Education Department (No. KY[2018]069).

\section{References}

[1] E. L. Kunkes, D. A. Simonetti, R. M. West, J. C. Serrano-Ruiz, C. A. Gartner, and J. A. Dumesic, "Catalytic conversion of biomass to monofunctional hydrocarbons and targeted liquid-fuel classes," Science, vol. 322, no. 5900, pp. 417-421, 2008.

[2] D. R. Dodds and R. A. Gross, "Chemicals from biomass," Science, vol. 318, no. 5854, pp. 1250-1251, 2007.

[3] P. Gallezot, "Conversion of biomass to selected chemical products," Chemical Society Reviews, vol. 41, no. 4, pp. 1538-1558, 2012.

[4] R. J. Putten, J. C. Waal, E. Jong, C. B. Rasrendra, H. J. Heeres, and J. G. Vries, "Hydroxymethylfurfural, a versatile platform chemical made from renewable resources," Chemical Reviews, vol. 113, no. 3, pp. 1499-1597, 2013.

[5] J. C. Serrano-Ruiz, R. Luque, and A. Sepúlveda-Escribano, "Transformations of biomass-derived platform molecules: from high added-value chemicals to fuelsvia aqueous-phase processing," Chemical Society Reviews, vol. 40, no. 11, pp. 5266-5281, 2011.

[6] K. Yan, G. Wu, T. Lafleur, and C. Jarvis, "Production, properties and catalytic hydrogenation of furfural to fuel additives and value-added chemicals Renewable Sustainable," Renewable and Sustainable Energy Reviews, vol. 38, pp. 663676, 2014.
[7] J. B. Binder and R. T. Raines, "Simple chemical transformation of lignocellulosic biomass into furans for fuels and chemicals," Journal of the American Chemical Society, vol. 131, no. 5, pp. 1979-1985, 2009.

[8] J. N. Chheda, G. W. Huber, and J. A. Dumesic, "Liquidphase catalytic processing of biomass-derived oxygenated hydrocarbons to fuels and chemicals Angew," Angewandte Chemie International Edition, vol. 46, no. 38, pp. 7164-7183, 2007.

[9] Y. Zhang, Z. Xue, J. Wang et al., "Controlled deposition of Pt nanoparticles on $\mathrm{Fe}_{3} \mathrm{O}_{4} @$ carbon microspheres for efficient oxidation of 5-hydroxymethylfurfural," RSC Advances, vol. 6, no. 56, pp. 51229-51237, 2016.

[10] E. Taarning, I. S. Nielsen, K. Egeblad, R. Madsen, and Christensen, "Chemicals from renewables: aerobic oxidation of furfural and hydroxymethylfurfural over gold catalysts," ChemSusChem, vol. 1, no. 1-2, pp. 75-78, 2008.

[11] H. Omidvarborna, A. Kumar, and D. S. Kim, "Recent studies on soot modeling for diesel combustion," Renewable and Sustainable Energy Reviews, vol. 48, pp. 635-647, 2015.

[12] H. Omidvarborna, A. Kumar, and D. S. Kim, "Characterization of particulate matter emitted from transit fueled with B20 in idle modes," Journal of Environmental Chemical Engineering, vol. 2, no. 4, pp. 2335-2342, 2014.

[13] G. W. Huber, S. Iborra, and A. Corma, "Synthesis of transportation fuels from biomass: chemistry, catalysts, and engineering," Chemical Reviews, vol. 106, no. 9, pp. 4044-4098, 2006.

[14] T. Werpy, G. Petersen, A. Aden, J. Bozell, J. Holladay, and J. White, Top Value Added Chemicals from Biomass. Volume 1-Results of Screening for Potential Candidates from Sugars and Synthesis Gas, Department of Energy Washington DC, Washington, DC, USA, 2004.

[15] B. Kamm, P. R. Gruber, and M. Kamm, BiorefineriesIndustrial Processes and Products, John Wiley \& Sons, Hoboken, NY, USA, 2007.

[16] M. J. Murphy, J. D. Taylor, and R. L. McCormick, "Compendium of experimental cetane number data," NREL/SR540-36805, National Renewable Energy Laboratory, Golden, Colorado, 2004.

[17] J. S. Câmara, M. A. Alves, and J. C. Marques, "Changes in volatile composition of Madeira wines during their oxidative ageing," Analytica Chimica Acta, vol. 563, no. 1-2, pp. 188197, 2006.

[18] B. Vanderhaegen, H. Neven, S. Coghe, K. J. Verstrepen, H. Verachtert, and G. Derdelinckx, "Evolution of chemical and sensory properties during aging of top-fermented beer," Journal of Agricultural and Food Chemistry, vol. 51, no. 23, pp. 6782-6790, 2003.

[19] M. S. Pérez-Coello, M. A. González-Viñas, E. Garcia-Romero, M. C. Diaz-Maroto, and M. D. Cabezudo, "Influence of storage temperature on the volatile compounds of young white wines," Food Control, vol. 14, no. 5, pp. 301-306, 2003.

[20] S. H. Oliveira, P. P. Guedes, B. P. Machado, T. Hogg, J. C. Marques, and J. S. Câmara, "Impact of forced-aging process on Madeira wine flavor," Journal of Agricultural and Food Chemistry, vol. 56, no. 24, pp. 11989-11996, 2008.

[21] I. Cutzach, P. Chatonnet, and D. Dubourdieu, "Study of the formation mechanisms of some volatile compounds during the aging of sweet fortified wines," Journal of Agricultural and Food Chemistry, vol. 47, no. 7, pp. 2837-2846, 1999.

[22] G. J. M. Gruter and F. Dautzenberg, "Method for the synthesis of 5-hydroxy-methylfurfural ethers and their use," U.S. Patent/0082304 A1, 2011. 
[23] H. Omidvarborna, A. Kumar, and D. S. Kim, "Variation of diesel soot characteristics by different types and blends of biodiesel in a laboratory combustion chamber," Science of The Total Environment, vol. 544, pp. 450-459, 2016.

[24] B. Liu and Z. H. Zhang, "One-pot conversion of carbohydrates into furan derivatives via furfural and 5-hydroxylmethylfurfural as intermediates," ChemSusChem, vol. 9, no. 16, pp. 1-23, 2016.

[25] M. E. Janka, D. M. Lange, M. C. Morrow et al., "Oxidation process to produce a crude and/or purified carboxylic acid product," US patent 2012/0302770A1, 2012.

[26] A. Bredihhin, S. Luiga, and L. Vares, "Application of 5ethoxymethylfurfural (EMF) for the production of cyclopentenones," Synthesis, vol. 48, no. 23, pp. 4181-4188, 2016.

[27] S. Alipour, H. Omidvarborna, and D. S. Kim, "A review on synthesis of alkoxymethyl furfural, a biofuel candidate," Renewable and Sustainable Energy Reviews, vol. 71, pp. 908-926, 2017.

[28] M. Balakrishnan, E. R. Sacia, and A. T. Bell, "Etherification and reductive etherification of 5-(hydroxymethyl) furfural: 5(alkoxymethyl) furfurals and 2,5-bis (alkoxymethyl) furans as potential bio-diesel candidates," Green Chemistry, vol. 14, no. 6, pp. 1626-1634, 2012.

[29] P. Lanzafame, D. M. Temi, S. Perathoner et al., "Etherification of 5-hydroxymethyl-2-furfural (HMF) with ethanol to biodiesel components using mesoporous solid acidic catalysts," Catalysis Today, vol. 175, no. 1, pp. 435-441, 2011.

[30] P. H. Che, F. Lu, J. J. Zhang et al., "Catalytic selective etherification of hydroxyl groups in 5-hydroxymethylfurfural over $\mathrm{H}_{4} \mathrm{SiW}_{12} \mathrm{O}_{40} / \mathrm{MCM}-41$ nanospheres for liquid fuel production," Bioresource Technology, vol. 119, pp. 433-436, 2012.

[31] B. Liu, Z. H. Zhang, K. , C. Huang, and Z. F. Fang, "Efficient conversion of carbohydrates into 5-ethoxymethylfurfural in ethanol catalyzed by $\mathrm{AlCl}_{3}$," Fuel, vol. 113, pp. 625-631, 2013.

[32] J. T. Liu, Y. Tang, K. G. Wu, C. F. Bi, and Q. Cui, "Conversion of fructose into 5-hydroxymethylfurfural(HMF) and its derivatives promoted by inorganic salt in alcohol," Carbohydrate Research, vol. 350, pp. 20-24, 2012.

[33] Y. Yang, C. W. Hu, and M. M. Abu-Omar, "Conversion of glucose into furans in the presence of $\mathrm{AlCl}_{3}$ in an ethanolwater solvent system," Bioresource Technology, vol. 116, pp. 190-194, 2012.

[34] X. Yu, X. Y. Gao, R. L. Tao, and L. C. Peng, "Insights into the metal salt Catalyzed 5-ethoxymethylfurfural synthesis from carbohydrates," Catalysts, vol. 7, no. 6, pp. 182-192, 2017.

[35] X. Q. Jia, J. P. Ma, P. H. Che et al., "Direct conversion of fructose-based carbohydrates to 5-ethoxymethylfurfural catalyzed by $\mathrm{AlCl}_{3} \cdot 6 \mathrm{H}_{2} \mathrm{O} / \mathrm{BF}_{3}(\mathrm{Et})_{2} \mathrm{O}$ in ethanol," Journal of Energy Chemistry, vol. 22, no. 1, pp. 93-97, 2013.

[36] X. M. Zhou, Z. H. Zhang, B. Liu, Q. Zhou, S. G. Wang, and K. J. Deng, "Catalytic conversion of fructose into furans using $\mathrm{FeCl}_{3}$ as catalyst," Journal of Industrial and Engineering Chemistry, vol. 20, no. 2, pp. 644-649, 2014.

[37] M. I. Alam, S. De, S. Dutta, and B. Saha, "Solid-acid and ionicliquid catalyzed one-pot transformation of biorenewable substrates into a platform chemical and a promising biofuel," RSC Advances, vol. 2, no. 17, pp. 6890-6896, 2012.

[38] S. Saravanamurugan and A. Riisager, "Solid acid catalysed formation of ethyl levulinate and ethyl glucopyranoside from mono-and disaccharides," Catalysis Communications, vol. 17, pp. 71-75, 2012.

[39] P. Neves, M. M. Antunes, P. A. Russo et al., "Production of biomass-derived furanic ethers and levulinate esters using heterogeneous acid catalysts," Green Chemistry, vol. 15, no. 12, pp. 3367-3376, 2013.

[40] A. Q. Liu, Z. H. Zhang, Z. F. Fang, B. Liu, and K. C. Huang, "Synthesis of 5-ethoxymethylfurfural from 5-hydroxymethylfurfural and fructose in ethanol catalyzed by MCM-41 supported phosphotungstic acid," Journal of Industrial and Engineering Chemistry, vol. 20, no. 4, pp. 1977-1984, 2014.

[41] C. M. Lew, N. Rajabbeigi, and M. Tsapatsis, "One-pot synthesis of 5-(ethoxymethyl)furfural from glucose using Sn-BEA and Amberlyst catalysts," Industrial \& Engineering Chemistry Research, vol. 51, no. 14, pp. 5364-5366, 2012.

[42] H. Li, S. Saravanamurugan, S. Yang, and A. Riisager, "Direct transformation of carbohydrates to the biofuel 5-ethoxymethylfurfural by solid acid catalysts," Green Chem, vol. 18, no. 3, pp. 726-734, 2016.

[43] J. D. Lewis, S. V. Vyver, A. J. Crisci et al., "A continuous flow strategy for the coupled transfer hydrogenation and etherification of 5-(hydroxymethyl)furfural using lewis acid zeolites," ChemSusChem, vol. 7, no. 8, pp. 2255-2265, 2014.

[44] K. Barbera, P. Lanzafame, S. Perathoner et al., "HMF etherification using $\mathrm{NH}_{4}$-exchanged zeolites," New Journal of Chemistry, vol. 40, no. 5, pp. 4300-4306, 2016.

[45] Y. Y. Bai, L. Wei, M. F. Yang et al., “Three-step cascade over a single catalyst: synthesis of 5-(ethoxymethyl)furfural from glucose over a hierarchical lamellar multi-functional zeolite catalyst," Journal of Materials Chemistry A, vol. 6, no. 17, pp. 7693-7705, 2018.

[46] Y. Yang, M. M. Abu-Omar, and C. W. Hu, "Heteropolyacid catalyzed conversion of fructose, sucrose, and inulin to 5ethoxymethylfurfural, a liquid biofuel candidate," Appl. Energy, vol. 99, pp. 80-84, 2012.

[47] H. L. Wang, T. S. Deng, Y. X. Wang, Y. Q. Qi, X. L. Hou, and Y. L. Zhu, "Efficient catalytic system for the conversion of fructose into 5-ethoxymethylfurfural," Bioresource Technology, vol. 136, pp. 394-400, 2013.

[48] Y. Ren, B. Liu, Z. Zhang, and J. Lin, "Silver-exchanged heteropolyacid catalyst $\left(\mathrm{Ag}_{1} \mathrm{H}_{2} \mathrm{PW}\right)$ : an efficient heterogeneous catalyst for the synthesis of 5-ethoxymethylfurfural from 5hydroxymethylfurfural and fructose," Journal of Industrial and Engineering Chemistry, vol. 21, pp. 1127-1131, 2015.

[49] L. H. Reddy, J. L. Arias, J. Nicolas, and P. Couvreur, "Magnetic nanoparticles: design and characterization, toxicity and biocompatibility, pharmaceutical and biomedical applications," Chemical Reviews, vol. 112, no. 11, pp. 5818-5178, 2012.

[50] S. G. Wang, Z. H. Zhang, B. Liu, and J. L. Li, "Silica coated magnetic $\mathrm{Fe}_{3} \mathrm{O}_{4}$ nanoparticles supported phosphotungstic acid: a novel environmentally friendly catalyst for the synthesis of 5ethoxymethylfurfural from 5-hydroxymethylfurfural and fructose," Catalysis Science \& Technology, vol. 3, no. 8, pp. 2104-2112, 2013.

[51] B. Liu and Z. H. Zhang, "One-pot conversion of carbohydrates into 5-ethoxymethylfurfural and ethyl D-glucopyranoside in ethanol catalyzed by a silica supported sulfonic acid catalyst," RSC Advances, vol. 3, no. 30, pp. 12313-12319, 2013.

[52] B. Liu, Z. H. Zhang, and K. J. Deng, "Efficient one-pot synthesis of 5-(ethoxymethyl) furfural from fructose catalyzed by a novel solid catalyst," Industrial \& Engineering Chemistry Research, vol. 51, no. 47, pp. 15331-15336, 2012.

[53] Z. W. Wang, H. Li, C. J. Fang, W. F. Zhao, T. T. Yang, and S. Yang, "Simply assembled acidic nanospheres for efficient production of 5-ethoxymethylfurfural from 5-hydromethylfurfural and fructose," Energy Technology, vol. 5, no. 11, pp. 2046-2054, 2017. 
[54] A. Q. Liu, B. Liu, Y. M. Wang, R. S. Ren, and Z. H. Zhang, "Efficient one-pot synthesis of 5-ethoxymethylfurfural from fructose catalyzed by heteropolyacid supported on K-10 clay," Fuel, vol. 117, pp. 68-73, 2014.

[55] Z. H. Wang and Q. W. Chen, "Conversion of 5-hydroxymethylfurfural into 5-ethoxymethylfurfural and ethyl levulinate catalyzed by MOF-based heteropolyacid materials," Green Chemistry, vol. 18, no. 21, pp. 5884-5889, 2016.

[56] G. Z. Xu, B. L. Chen, Z. B. Zheng, K. Li, and H. G. Tao, "Onepot ethanolysis of carbohydrates to promising biofuels: 5ethoxymethylfurfural and ethyl levulinate," Asia-Pacific Journal of Chemical Engineering, vol. 12, no. 4, pp. 527535, 2017.

[57] H. Li, K. S. Govind, R. Kotni, S. Shunmugavel, A. Riisager, and S. Yang, "Direct catalytic transformation of carbohydrates into 5-ethoxymethylfurfural with acid-base bifunctional hybrid nanospheres," Energy Conversion and Management, vol. 88, pp. 1245-1251, 2014.

[58] H. S. Xin, T. W. Zhang, W. Z. Li et al., "Dehydration of glucose to 5-hydroxymethylfurfural and 5-ethoxymethylfurfural by combining Lewis and Brønsted acid," RSC Advances, vol. 7, no. 66, pp. 41546-41551, 2017.

[59] G. Raveendra, A. Rajasekhar, M. Srinivas, P. S. S. Prasad, and N. Lingaiah, "Selective etherification of hydroxymethylfurfural to biofuel additivesover Cs containing silicotungstic acid catalysts G," Applied Catalysis A: General, vol. 520, pp. 105-113, 2016.

[60] Z. H. Zhang, Y. M. Wang, Z. F. Fang, and B. Liu, "Synthesis of 5-ethoxymethylfurfural from fructose and inulin catalyzed by a magnetically recoverable acid catalyst," ChemPlusChem, vol. 79, no. 2, pp. 233-240, 2014.

[61] Z. L. Yuan, Z. H. Zhang, J. D. Zheng, and J. T. Lin, "Efficient synthesis of promising liquid fuels 5-ethoxymethylfurfural from carbohydrates,” Fuel, vol. 150, pp. 236-242, 2015.

[62] S. S. Yin, J. Sun, B. Liu, and Z. H. Zhang, "Magnetic material grafted cross-linked imidazolium based polyionic liquids: an efficient acid catalyst for the synthesis of promising liquid fuel 5-ethoxymethylfurfural from carbohydrates," Journal of Materials Chemistry A, vol. 3, no. 9, pp. 4992-4999, 2015.

[63] J. M. Wang, Z. H. Zhang, S. W. Jin, and X. Z. Shen, "Efficient conversion of carbohydrates into 5-hydroxylmethylfurfan and 5-ethoxymethylfurfural over sufonic acid-functionalized mesoporous carbon catalyst," Fuel, vol. 192, pp. 102-107, 2017.

[64] Y. Yao, A. Gu, Y. Wang, H. J. Wang, and W. Li, "Magnetically recoverable carbonaceous material: an efficient catalyst for the synthesis of 5-hydroxymethylfurfural and 5-ethoxymethylfurfural from carbohydrates," Russian Journal of General Chemistry, vol. 86, no. 7, pp. 1698-1704, 2016.

[65] H. L. Wang, T. S. Deng, Y. X. Wang et al., "Graphene oxide as a facile acid catalyst for the one-pot conversion of carbohydrates into 5-ethoxymethylfurfural," Green Chemistry, vol. 15, no. 9, pp. 2379-2383, 2013.

[66] M. M. Antunes, P. A. Russo, P. V. Wiper et al., "Sulfonated graphene oxide as effective catalyst for conversion of 5(hydroxymethyl)-2-furfural into biofuels," ChemSusChem, vol. 7, no. 3, pp. 804-812, 2014.

[67] B. Liu, Z. H. Zhang, and K. C. Huang, "Cellulose sulfuric acid as a bio-supported and recyclable solid acid catalyst for the synthesis of 5-hydroxymethylfurfural and 5-ethoxymethylfurfural from fructose," Cellulose, vol. 20, no. 4, pp. 2081-2089, 2013.
[68] R. S. Thombal and V. H. Jadhav, "Application of glucose derived magnetic solid acid for etherification of 5-HMF to 5EMF, dehydration of sorbitol to isosorbide, and esterification of fatty acids," Tetrahedron Letters, vol. 57, no. 39, pp. 4398-4400, 2016.

[69] H. Zhu, Q. Cao, C. H. Li, and X. Mu, "Acidic resin-catalysed conversion of fructose into furan derivatives in low boiling point solvents," Carbohydrate Research, vol. 346, no. 13, pp. 2016-2018, 2011.

[70] G. Morales, M. Paniagua, J. A. Melero, and J. Iglesias, "Efficient production of 5-ethoxymethylfurfural from fructose by sulfonic mesostructured silica using DMSO as co-solvent," Catalysis Today, vol. 279, pp. 305-316, 2017.

[71] H. Li, Q. Y. Zhang, and S. Yang, "Catalytic cascade dehydration-etherification of fructose into 5-ethoxymethylfurfural with $\mathrm{SO}_{3} \mathrm{H}$-functionalized polymers," International Journal of Chemical Engineering, vol. 2014, Article ID 481627, 7 pages, 2014.

[72] G. A. Kraus and T. Guney, "A direct synthesis of 5-alkoxymethylfurfural ethers from fructose via sulfonic acidfunctionalized ionic liquids," Green Chemistry, vol. 14, no. 6, pp. 1593-1596, 2012.

[73] S. De, S. Dutta, and B. Saha, "One-pot conversions of lignocellulosic and algal biomass into liquid fuels," ChemSusChem, vol. 5, no. 9, pp. 1826-1833, 2012.

[74] H. X. Guo, X. H. Qi, Y. Y. Hiraga, T. M. Aida, and R. L. Smith, "Efficient conversion of fructose into 5-ethoxymethylfurfural with hydrogen sulfate ionic liquids as co-solvent and catalyst," Chemical Engineering Journal, vol. 314, pp. 508-514.

[75] M. Zuo, K. Le, Y. C. Feng et al., "An effective pathway for converting carbohydrates to biofuel 5-ethoxymethylfurfural via 5-hydroxymethylfurfural with deep eutectic solvents (DESs)," Industrial Crops and Products, vol. 112, pp. 18-23, 2018.

[76] S. Shinde and C. Rode, "Cascade reductive etherification of bioderived aldehydes over Zr-based catalysts," ChemSusChem, vol. 10, no. 20, pp. 4090-4101, 2017.

[77] K. K. Yadav, S. Ahmad, and S. M. S. Chauhan, "Elucidating the role of cobalt phthalocyanine in the dehydration of carbohydrates in ionic liquids," Journal of Molecular Catalysis A: Chemical, vol. 394, pp. 170-176, 2014.

[78] I. Viil, A. Bredihhin, U. Mäeorgb, and L. Vares, "Preparation of potential biofuel 5-ethoxymethylfurfural and other 5alkoxymethylfurfurals in the presence of oil shale ash," $R S C$ Advances, vol. 4, no. 11, pp. 5689-5693, 2014.

[79] J. G. Pereira, S. C. A. Sousa, and C. A. Fernandes, "Direct conversion of carbohydrates into 5-ethoxymethylfurfural (EMF) and 5-hydroxymethylfurfural (HMF) catalyzed by oxomolybdenum complexes," ChemistrySelect, vol. 2, no. 16, pp. 4516-4521, 2017.

[80] B. Kim, J. Jeong, S. Shin et al., "Facile single-step conversion of macroalgal polymeric carbohydrates into biofuels," ChemSusChem, vol. 3, no. 11, pp. 1273-1275, 2010.

[81] R. J. Grisel, J. C. van der Waal, E. de Jong, and W. J. Huijgen, "Acid catalysed alcoholysis of wheat straw: towards second generation furan-derivatives," Catalysis Today, vol. 223, pp. 3-10, 2014.

[82] A. I. Torres, P. Daoutidis, and M. Tsapatsis, "Continuous production of 5-hydroxymethylfurfural from fructose: a design case study," Energy \& Environmental Science, vol. 3, no. 10, pp. 1560-1572, 2010.

[83] Y. Román-Leshkov, J. N. Chheda, and J. A. Dumesic, "Phase modifiers promote efficient production of hydroxymethylfurfural from fructose," Science, vol. 312, no. 5782, pp. 1933-1937, 2006. 


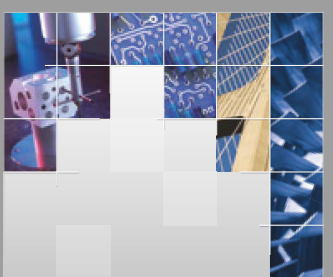

\section{Enfincering}
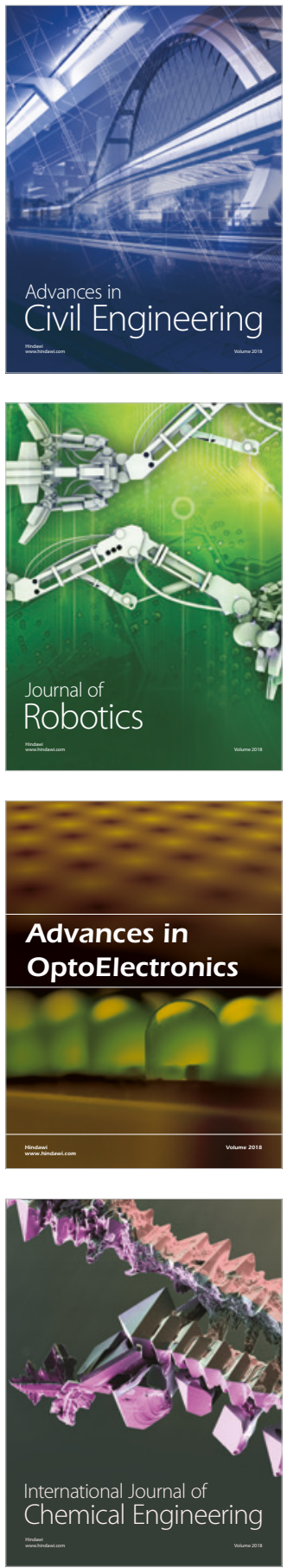

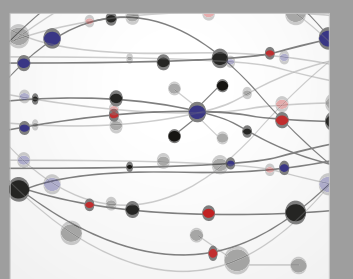

\section{Rotating \\ Machinery}

The Scientific World Journal

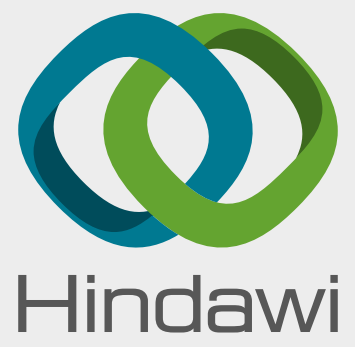

Submit your manuscripts at

www.hindawi.com
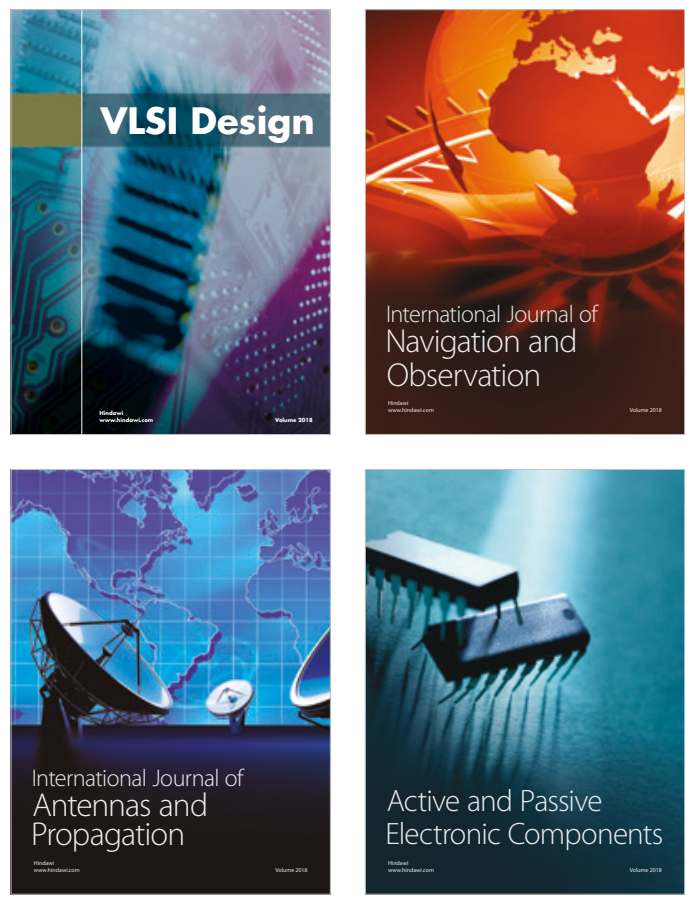
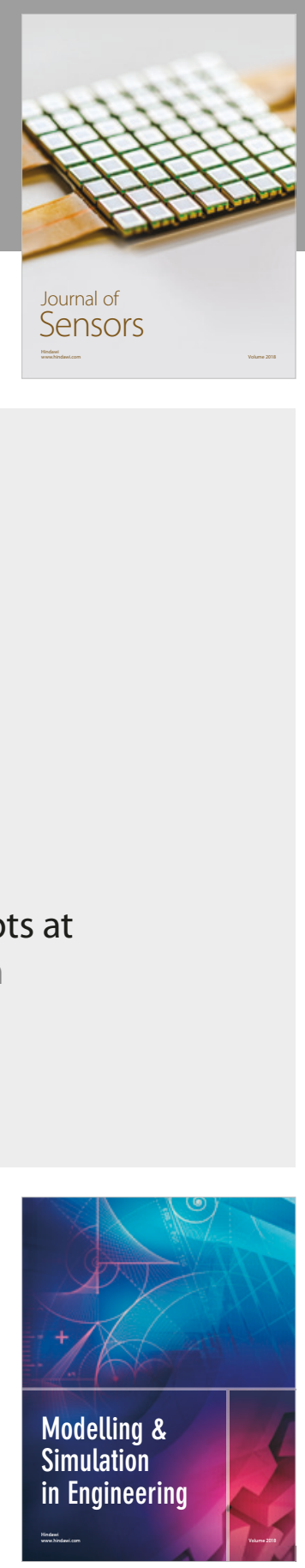

\section{Advances \\ Multimedia}
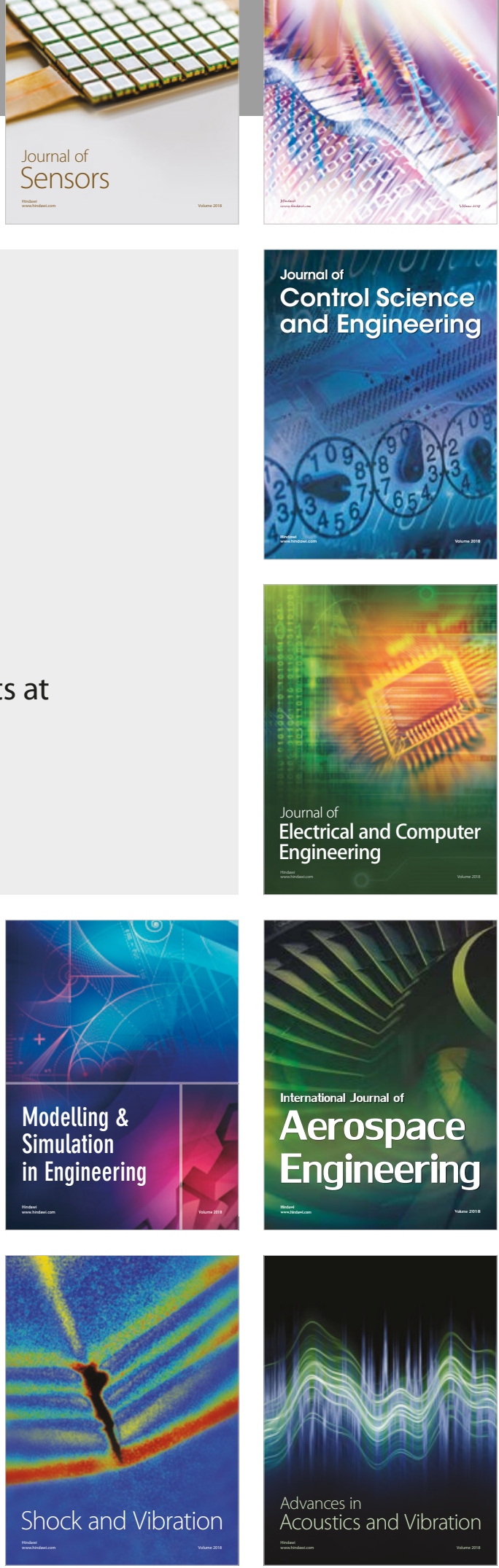